\title{
Performance Evaluation of Concrete Structures Using Crack Repair Methods
}

\author{
Tae-Kyun Kim * (1) and Jong-Sup Park
}

Citation: Kim, T.-K.; Park, J.-S

Performance Evaluation of Concrete Structures Using Crack Repair

Methods. Sustainability 2021, 13, 3217

https://doi.org/10.3390/su13063217

Academic Editor:

Constantin Chalioris

Received: 5 February 2021

Accepted: 13 March 2021

Published: 15 March 2021

Publisher's Note: MDPI stays neutral with regard to jurisdictional claims in published maps and institutional affiliations.

Copyright: (c) 2021 by the authors. Licensee MDPI, Basel, Switzerland. This article is an open access article distributed under the terms and conditions of the Creative Commons Attribution (CC BY) license (https:/ / creativecommons.org/licenses/by/ $4.0 /)$.
Advanced Composites Research Center, Korea Institute of Civil Engineering and Building Technology, 283, Goyang-daero, Ilsanseo-gu, Goyang-si 10223, Gyeonggi-do, Korea; jSpark1@kict.re.kr

* Correspondence: kimtaekyun@kict.re.kr

\begin{abstract}
Concrete structures deteriorate over time due to cracks induced by various physical, chemical, and environmental factors. This performance degradation not only reduces their service life but may lead to human casualties and other property damage as well. While concrete crack repair can help address this problem, the implementation of the optimal repair method is important according to the environmental conditions. In this study, epoxy, impregnating, and epoxy/impregnating methods were used to repair concrete cracks. Epoxy was used for crack injection, and a supernatant was used for surface protection. The epoxy/impregnating method was used to protect both cracked areas and surfaces. Activated cracks were induced using flexural strength tests, and the stiffness of the specimens according to the repair method was compared to examine the structural performance. In addition, after the flexural strength tests, the strength, carbonation, chloride, and freeze-thaw durability were evaluated for the concrete core specimens. The impregnating method yielded the best repair performance for strength, epoxy/impregnating method for carbonation, epoxy and epoxy/impregnating methods for chloride, and epoxy/impregnating method for freezing and thawing. The results of our study enable selection of the optimal repair method to be used in practical applications based on physical, chemical, and environmental factors.
\end{abstract}

Keywords: concrete repair; epoxy and impregnating; carbonation; chloride; freeze and thaw

\section{Introduction}

Concrete structures undergo deterioration as they are exposed to chemical and environmental factors over time. These factors include carbonation, hydration heat, drying shrinkage, freezing and thawing, chloride, and alkali-aggregate reactions. Concrete cracking, as well as concrete spalling, and steel reinforcement corrosion, which are caused by internal and external chemical and physical reactions, occur as concrete deteriorates [1-3]. The service life of such concrete structures also decreases abruptly due to the degraded durability performance accompanied by structural defects. To address these problems, concrete repairs are required. Overseas standards and guidelines related to concrete repair include ISO-16311 of the International Organization for Standardization (ISO), EN-1504 standard of the European Union, and ACI 562 of the American Concrete Institute [4-6]. In South Korea, there are detailed guidelines on safety inspection and precision safety diagnosis implemented by the Korean Authority of Land and Infrastructure Safety, but they have only brief descriptions on crack repair [7]. In general, concrete repair methods are classified as (1) crack surface treatment methods, wherein a coat of paint is applied only to cracked areas to improve waterproofness and durability when the crack width is $0.2 \mathrm{~mm}$ or less; (2) crack injection methods, wherein a resin-based or cementitious material with low viscosity is injected into cracks to improve waterproofness and durability mostly when the crack width exceeds $0.2 \mathrm{~mm}$; and (3) crack filling methods, wherein concrete and mortar are cut along cracks in conjunction with the filling of the crack with a repair material when the crack width is $\geq 0.5 \mathrm{~mm}$ [7]. Repairs must be performed after the selection of suitable 
materials and the determination of the time considering the cause, range, and scale of cracking as well as environmental conditions, safety, and economic efficiency. At construction sites, however, repair methods are used in combination with an emphasis on safety. As this may increase maintenance costs, the implementation of the optimal repair method is important according to the environmental conditions [8]. In addition, South Korean research studies and guidelines related to repairs are still insufficient compared with those in other countries [8]. Nonetheless, considerable research efforts related to crack causes, materials, and repairs have been made in the past. Petrounias et al. [9] investigated how different alteration styles of serpentinites and andesites affect their mechanical properties, as well as how their performance as concrete aggregates is influenced. Issa et al. [10] used a single epoxy product and evaluated the performance of the material in artificial concrete cracks. Christodoulou et al. [11] evaluated the long-term performance of reinforced concrete structures following the use of surface-impregnating external silane coating. Kang et al. [12] evaluated the performance of crack repair materials based on the flexural specimens with inactive cracks through artificial notches. Bae et al. [13] evaluated the performance of concrete impregnated with inorganic surface penetration agents. Kwon et al. [14] performed surface impregnation repair on crack-free specimens and evaluated their durability. Most of these studies were conducted using specimens with no or inactive cracks and either developed new repair materials or evaluated the performance of a single material [9-14]. In this study, however, specimens to be applied to actual structures were fabricated, and then activated cracks were described for various loads. The induced cracks were then repaired, and the durability of the specimens evaluated. Durability degradation occurs in concrete infrastructure, including bridges, roads, tunnels, ports, and nuclear power plants, due to various deterioration phenomena [15-21]. To counter the effects of aging, the service life of such infrastructure must be extended via repairs and reinforcements [22-29]. Accordingly, the accuracy and effectiveness of repair and reinforcement technologies must be verified, and the construction of various experimental databases is first required to suggest improvement measures in terms of policies, systems, and economy in conjunction with technical factors.

Therefore, in this study, various tests were performed to examine the structural and durability performances according to the concrete crack repair method used. After the generation of artificial cracks in the specimens, areas with activated cracks were repaired using epoxy, impregnating, and epoxy/impregnating crack repair methods, and the structural performance of the specimens was evaluated. Subsequently, concrete core specimens were collected from the cracked areas to examine their durability performance based on the compressive strength of concrete, carbonation, accelerated carbonation, chloride, and freezing and thawing tests. Building new infrastructure requires significant resources. The results of this study contribute toward sustainability by shedding light on the optimal method to be used for extending the service life of existing concrete structures without compromising on safety.

\section{Materials and Methods}

\subsection{Structural Test Details and Methods}

In this study, artificial cracks were generated through an actual model beam to describe activated cracks. Figure 1 shows the details of the specimen and the experimental method. The specimen had a total length of $6400 \mathrm{~mm}$ and a height of $400 \mathrm{~mm}$. D22 rebars were used in three layers, and D10 was used as the tie bar. Supports were installed $200 \mathrm{~mm}$ from both ends. Loads were applied at points $900 \mathrm{~mm}$ from the top center of the specimen on both sides. To measure the displacement caused by the loads, a linear variable differential transformer (LVDT) was installed at the bottom center part of the specimen. The test was conducted using a 200 ton universal testing machine (UTM), and loading was controlled at a rate of $0.05 \mathrm{~mm} / \mathrm{s}$. TDS-503 was used for data measurements. In addition, the flexural strength tests were conducted in accordance with KS F 2408 (standard tests for the flexural strength of concrete). 


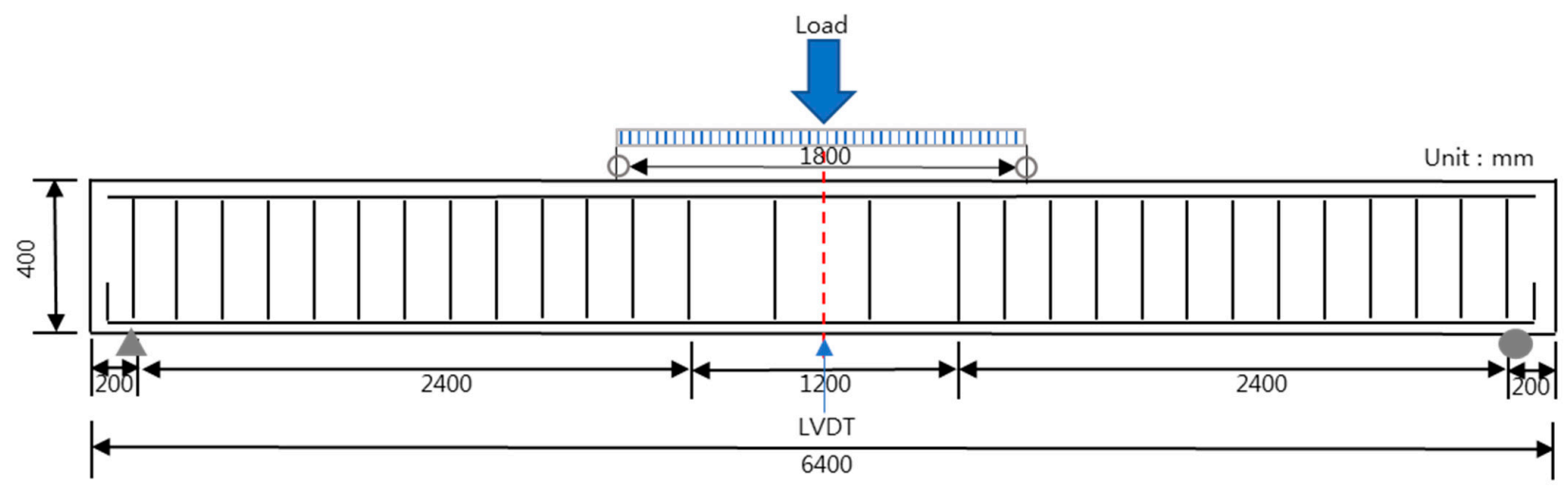

(a)

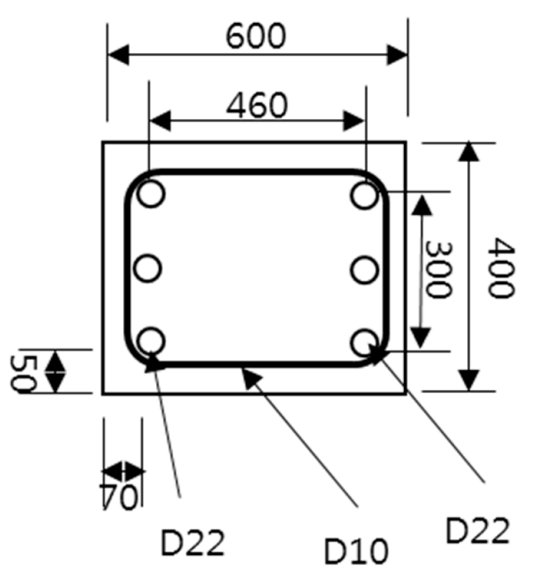

(b)

Figure 1. Test specimen details: (a) specimen details and (b) cross-sectional view.

\subsection{Crack Repair}

Figure 2 shows concrete crack repair methods. The epoxy, impregnating, and epoxy/ impregnating repair methods were used. Epoxy repairs fill cracks; impregnating repairs apply a coating to the concrete and crack surfaces; and epoxy/impregnating repairs fill the crack and protect the surface. The epoxy used in this study was a low-viscosity type (dry) mainly used for repairing cracks in concrete social infrastructure, such as bridges, tunnels, and dams (epoxy resin:polyamide amine $=2: 1$ ). In addition, the epoxy material had bond, tensile, and compressive strengths of 7.1, 61, and $60 \mathrm{MPa}$, respectively. It was injected using a syringe to fill the cracks. The impregnating material penetrates more than 3-6 mm when applied depending on the concrete strength. It also improves the durability and waterproofness of the concrete structure. Regarding the construction method, concrete cracks and foreign substances on the surface must be cleaned before impregnating it, and the structure must be sufficiently dried to improve the impregnating penetration effect. The surface was evenly impregnated using a roller and a sprayer.

\subsection{Reloading Flexural Strength Test}

The flexural strength test was performed as shown in Table 1. The test was conducted in two parts: (a) first loading, wherein concrete cracks were repaired and cured, and (b) second loading (approximately 80\% of the first loads). In the first loading, the 20, 30, and $40 \mathrm{MPa}$ specimens were subjected to maximum loads of 40,60, and $80 \mathrm{kN}$, followed by the removal of the loads. Reloading was then performed with loads of up to 20,40, and $60 \mathrm{kN}$. Upon the completion of the first loading, all the specimens were subjected to epoxy, impregnating, and epoxy/impregnating crack repairs and then cured for a certain 
period. Finally, in the second loading, loads of up to approximately $80 \%$ of the first loads, i.e., up to 30,50 , and $70 \mathrm{kN}$, were applied, and the load-displacement curves were plotted and analyzed.
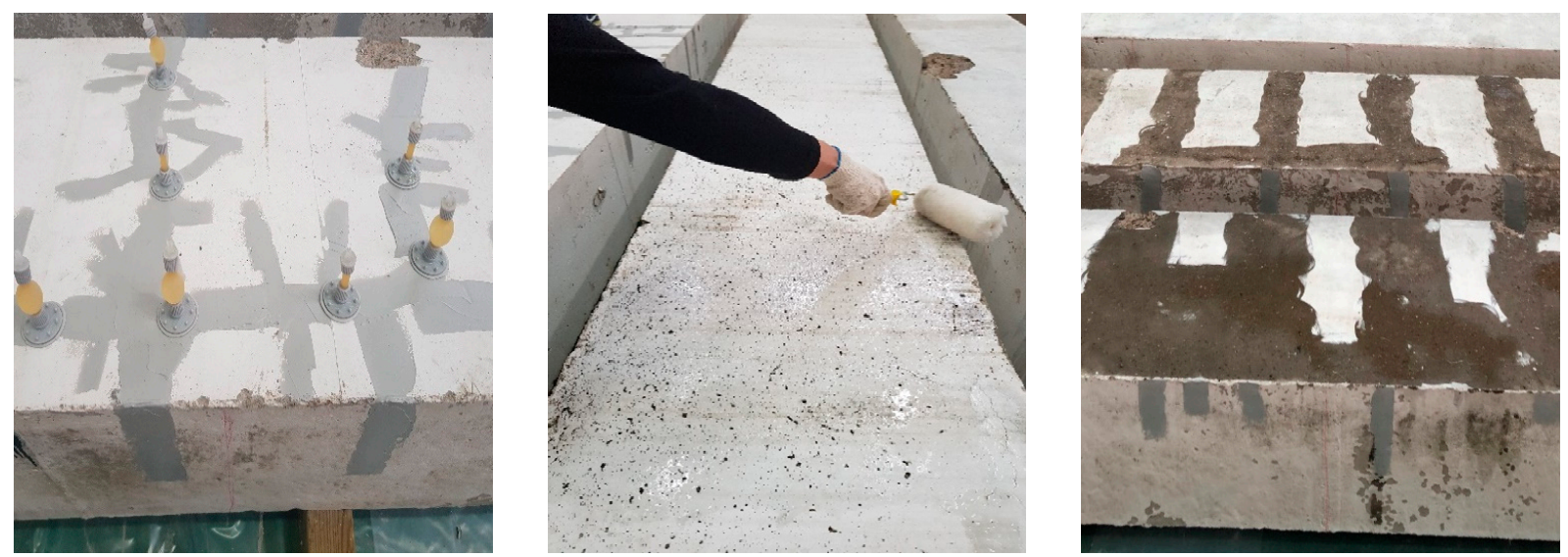

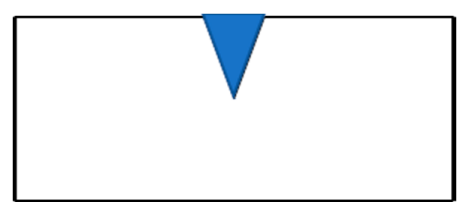

(a)

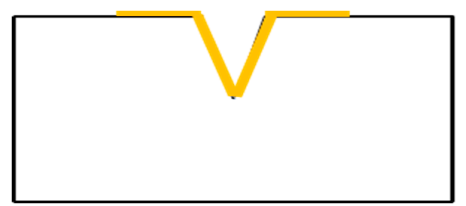

(b)

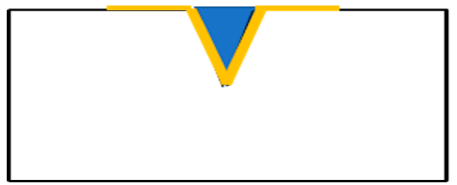

(c)

Figure 2. Crack repair methods: (a) epoxy repair, (b) impregnating repair, and (c) epoxy/impregnating repair.

Table 1. Loading and reloading methods of flexural strength test.

\begin{tabular}{|c|c|c|c|c|}
\hline Specimen & & First Loading & $\begin{array}{c}\text { Concrete Crack Repair and } \\
\text { Curing }\end{array}$ & Second Loading \\
\hline $20 \mathrm{MPa}$ & $\begin{array}{l}- \\
-\end{array}$ & $\begin{array}{l}\text { Loading up to } 40 \mathrm{kN} \\
\text { Load removal } \\
\text { Loading up to } 20 \mathrm{kN}\end{array}$ & $\begin{array}{l}\text { Epoxy } \\
\text { Impregnating } \\
\text { Epoxy/impregnating }\end{array}$ & Loading up to $30 \mathrm{kN}$ \\
\hline $30 \mathrm{MPa}$ & $\begin{array}{l}- \\
-\end{array}$ & $\begin{array}{l}\text { Loading up to } 60 \mathrm{kN} \\
\text { Load removal } \\
\text { Loading up to } 40 \mathrm{kN}\end{array}$ & $\begin{array}{l}\text { Epoxy } \\
\text { Impregnating } \\
\text { Epoxy/impregnating }\end{array}$ & Loading up to $50 \mathrm{kN}$ \\
\hline $40 \mathrm{MPa}$ & $\begin{array}{l}- \\
-\end{array}$ & $\begin{array}{l}\text { Loading up to } 80 \mathrm{kN} \\
\text { Load removal } \\
\text { Loading up to } 60 \mathrm{kN}\end{array}$ & $\begin{array}{l}\text { Epoxy } \\
\text { Impregnating } \\
\text { Epoxy/impregnating }\end{array}$ & Loading up to $70 \mathrm{kN}$ \\
\hline
\end{tabular}

\section{Results}

\subsection{Flexural Performance of Activated Crack Repair}

Figure 3 shows the flexural performance results of the $20 \mathrm{MPa}$ concrete specimens according to crack repair method in the form of load-displacement curves. After the application of each repair method and the second loading, the maximum deflections of the specimens repaired using epoxy, impregnating, and epoxy/impregnating methods were found to be 13.86, 13.21, and $15.22 \mathrm{~mm}$, respectively. When the results of the first loading were compared with those of the second loading after the repair, the stiffness increased by approximately $30 \%$ for epoxy repair, $2 \%$ for impregnating repair, and $46 \%$ for epoxy/impregnating repair. Epoxy and epoxy/impregnating repair exhibited a clear stiffness increase, but impregnating repair showed an insignificant increase. Regarding the 
crack patterns, cracks occurred from the existing cracks for impregnating repair, but cracks occurred at new locations for the repair methods that included epoxy.

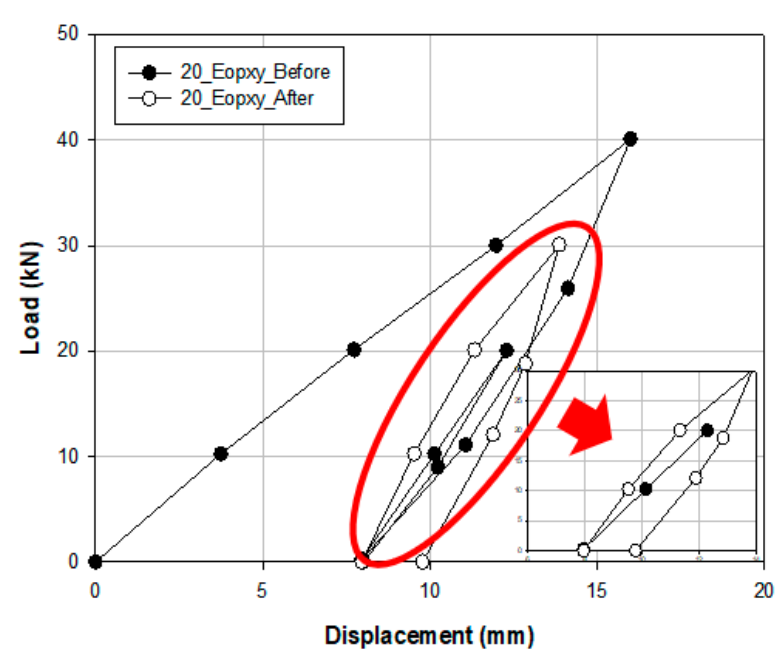

(a)

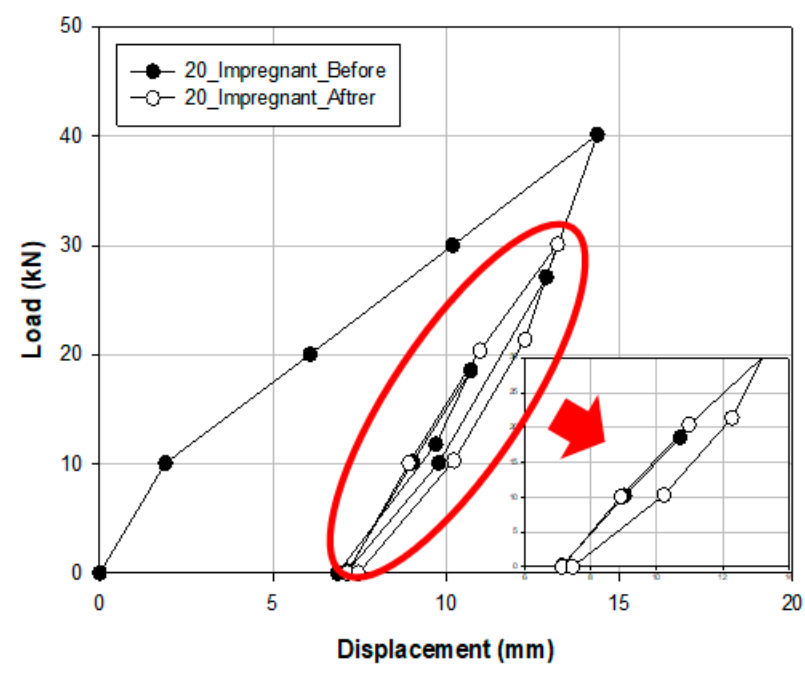

(b)

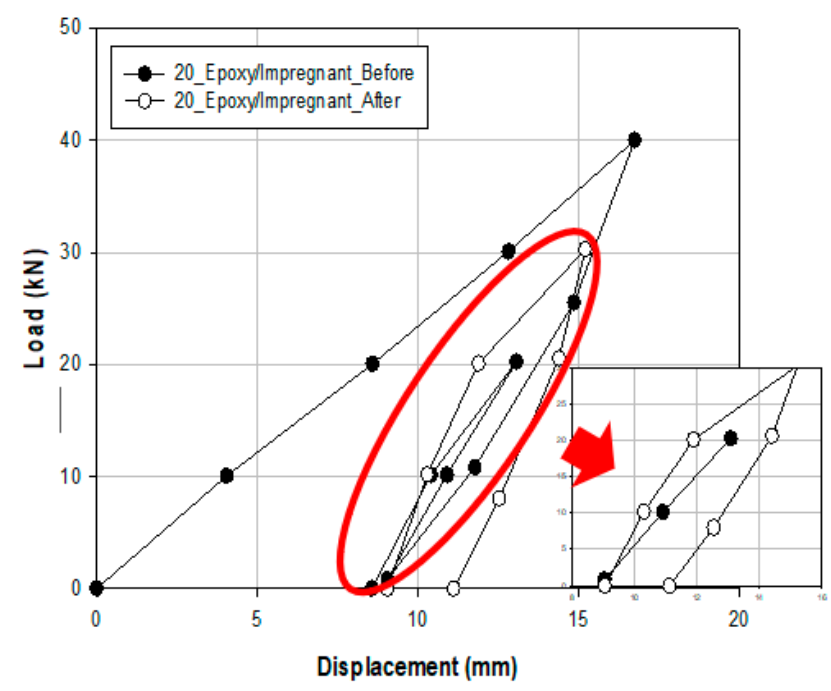

(c)

Figure 3. Flexural strength test results of $20 \mathrm{MPa}$ specimens: (a) epoxy repair, (b) impregnating repair, and (c) epoxy/ impregnating repair.

\subsection{Flexural Performance of $30 \mathrm{MPa}$ Activated Crack Repair}

Figure 4 shows the flexural performance results of the $30 \mathrm{MPa}$ concrete specimens according to crack repair method in the form of load-displacement curves. After the application of each repair method and the second loading, the maximum deflections of the specimens repaired using epoxy, impregnating, and epoxy/impregnating methods were found to be 22.82, 21.29, and $14.84 \mathrm{~mm}$, respectively. For the specimen repaired using epoxy/impregnating, however, significant cracking was observed during the first loading. Thus, the test was conducted under the same load conditions as the $20 \mathrm{MPa}$ specimen to prevent the fracture of the specimen. When the results of the first loading were compared with those of the second loading after the repairs, epoxy repair increased the stiffness by approximately $20 \%$. Impregnating repair decreased the stiffness by $6 \%$, and epoxy/impregnating repair exhibited the highest stiffness increase of $41 \%$. While epoxy and epoxy/impregnating repair methods exhibited a clear increase in stiffness, the increase was negligible for the impregnating repair method. Regarding the crack patterns, cracks 
occurred from the existing cracks in the case of impregnating repairs, but cracks occurred at new locations for the repair methods that included epoxy.

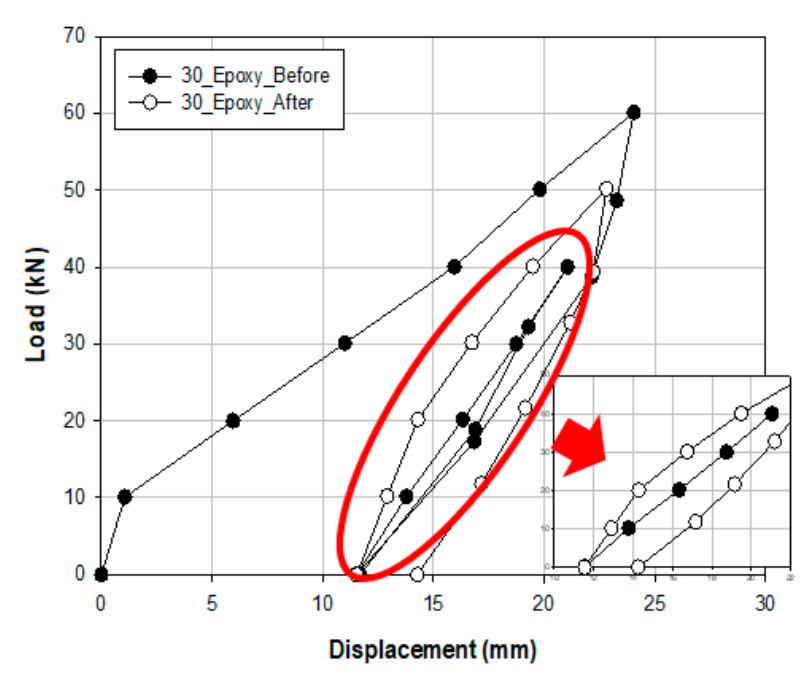

(a)

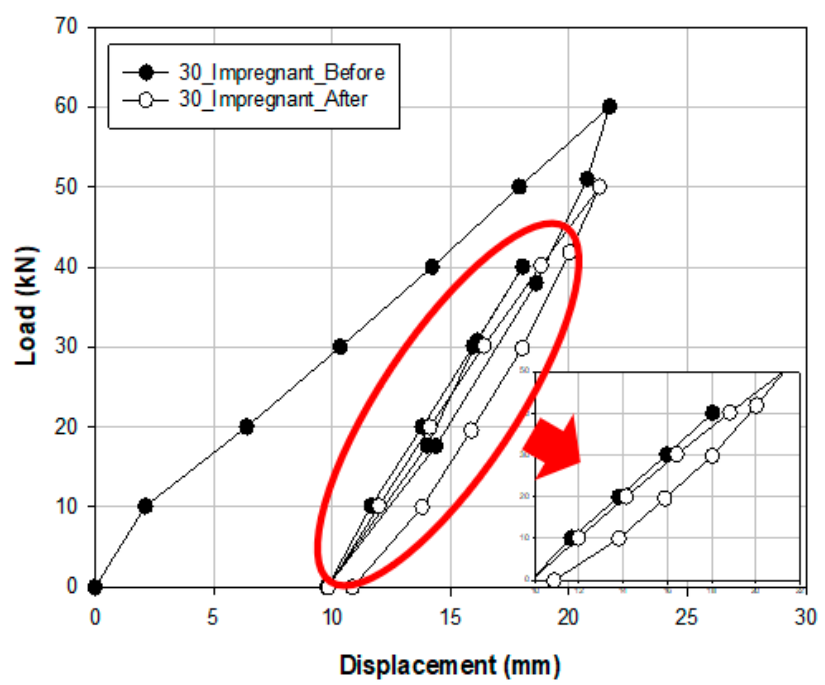

(b)

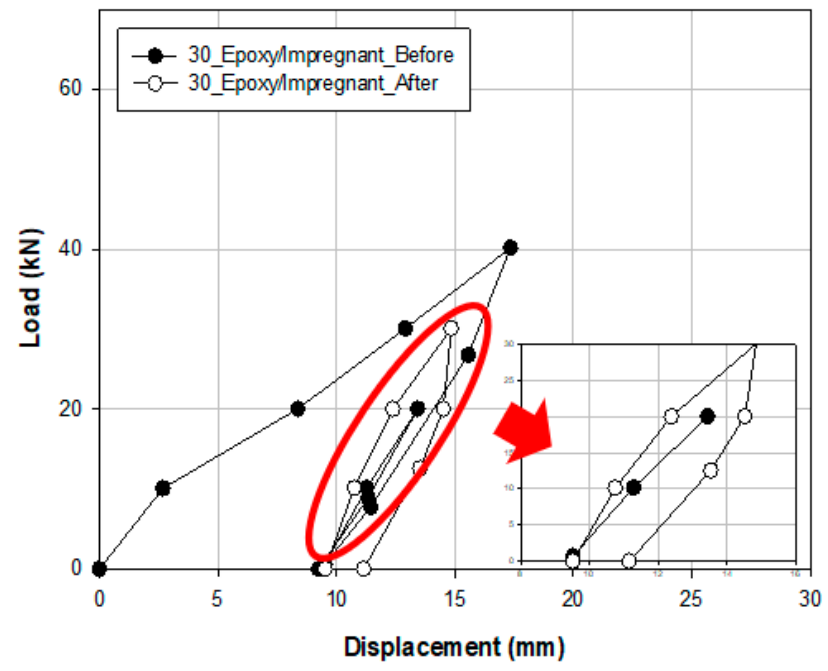

(c)

Figure 4. Flexural strength test results of $30 \mathrm{MPa}$ specimens: (a) epoxy, (b) impregnating, and (c) epoxy/impregnating repairs.

\subsection{Flexural Performance of Activated Crack Repair}

Figure 5 shows the flexural performance results of the $40 \mathrm{MPa}$ concrete specimens according to the crack repair method in the form of load-displacement curves. After the application of each repair method and the second loading, the maximum deflections of the specimens repaired using epoxy, impregnating, and epoxy/impregnating methods were found to be $30.83,27.06$, and $28.53 \mathrm{~mm}$, respectively. When the results of the first loading were compared with those of the second loading after repairs, the stiffness decreased by approximately $15 \%$ for epoxy repair, $12 \%$ for impregnating repair, and $13 \%$ for epoxy/impregnating repair. Epoxy repair maintained similar initial stiffness, unlike low and medium strengths, but the stiffness decreased as the load increased. Impregnating repair, however, exhibited low stiffness upon load application. Regarding crack patterns, cracks occurred from the existing cracks in the case of impregnating repair, but cracks occurred at new locations in the cases of repair methods that included epoxy. A comparison among the 20,30, and $40 \mathrm{MPa}$ specimens revealed that the repair methods 
related to epoxy repair significantly influenced the stiffness of the concrete structures as the strength increased.

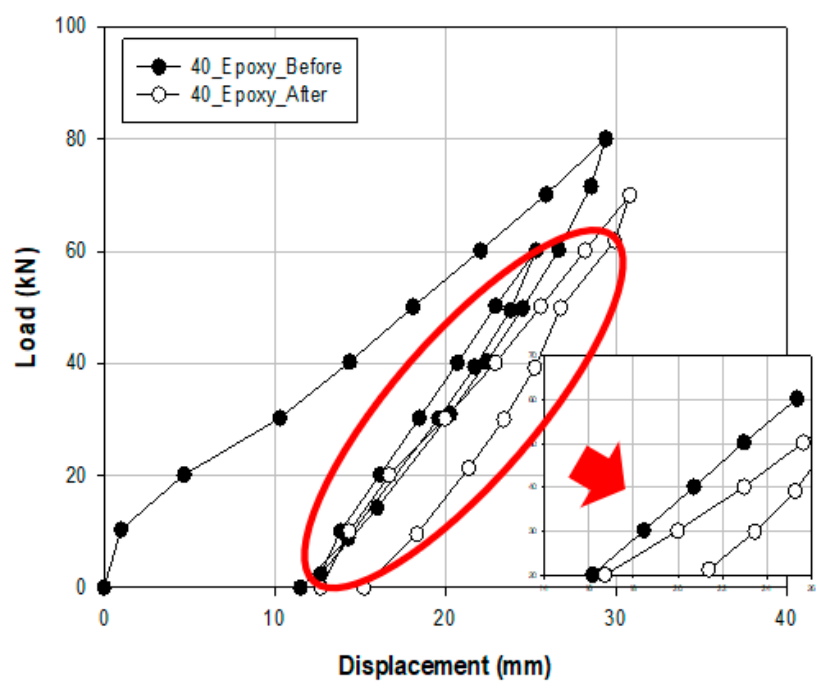

(a)

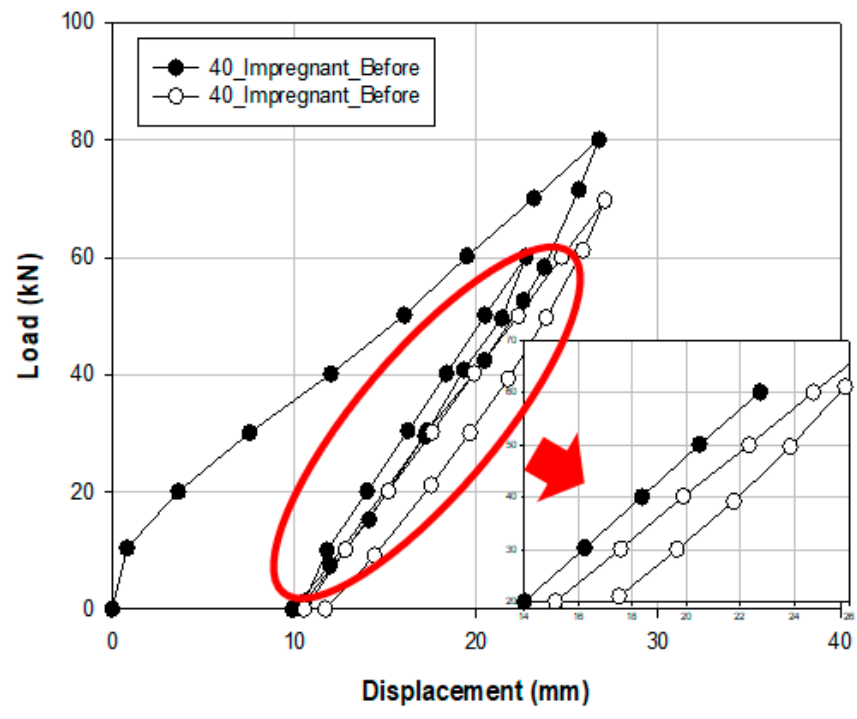

(b)

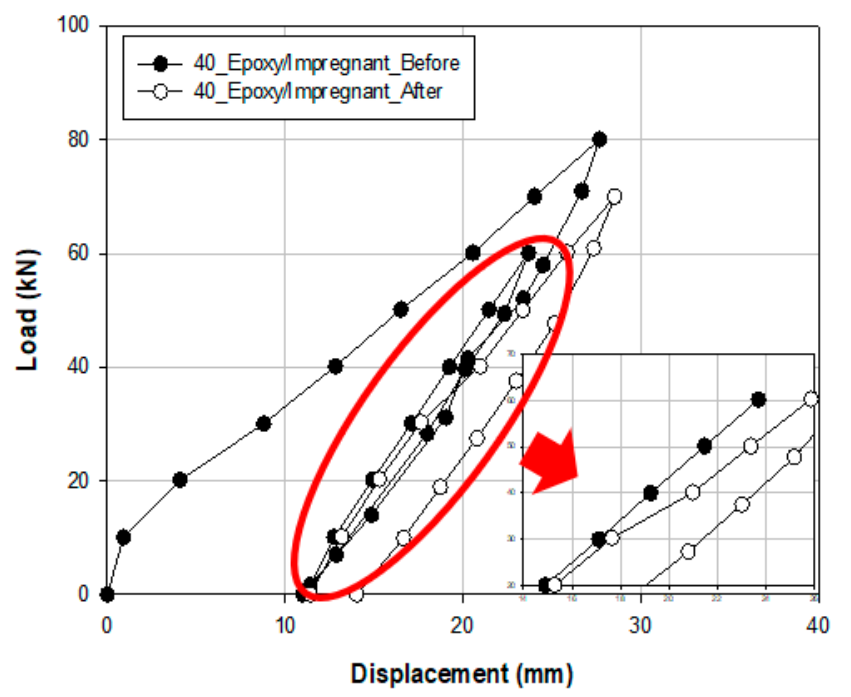

(c)

Figure 5. Flexural strength test results of $40 \mathrm{MPa}$ specimens: (a) epoxy, (b) impregnating, and (c) epoxy/impregnating repairs.

\section{Durability Evaluation Methods for Concrete Core Specimens}

\subsection{Concrete Core Specimens}

Table 2 presents the types and numbers of concrete core specimens. For the concrete core specimens, $\varnothing 100 \times 400$ cylindrical specimens with repaired cracks were collected upon the completion of the second loading flexural strength test. Three specimens were collected for each compressive strength, and another 48 specimens were collected for each strength repaired using epoxy, impregnating, and epoxy/impregnating methods. Carbonation, chloride, and freezing-thawing tests were conducted after cutting the specimens according to the durability standards for carbonation, chloride, freezing, and thawing. 


\subsection{Compressive Strength}

The concrete compressive strength test was conducted in accordance with the standard test method for the compressive strength of concrete, KS F 2405. In the test, a 200 ton UTM was used [30]. The specimen size was $\varnothing 100 \times 200 \mathrm{~mm}$.

Table 2. Concrete core specimens.

\begin{tabular}{|c|c|c|c|}
\hline Specimen & Design Strength (MPa) & EA & Durability Test \\
\hline \multirow{3}{*}{ Control } & 20 & 3 & \multirow{3}{*}{ Compressive strength } \\
\hline & 30 & 3 & \\
\hline & 40 & 3 & \\
\hline \multirow{3}{*}{ Epoxy } & 20 & 12 & \multirow{9}{*}{$\begin{array}{l}\text { Carbonation, chloride, } \\
\text { freezing-thawing, } \\
\text { compressive strength }\end{array}$} \\
\hline & 30 & 12 & \\
\hline & 40 & 12 & \\
\hline \multirow{3}{*}{ Impregnating } & 20 & 12 & \\
\hline & 30 & 12 & \\
\hline & 40 & 12 & \\
\hline \multirow{3}{*}{ Epoxy/Impregnating } & 20 & 12 & \\
\hline & 30 & 12 & \\
\hline & 40 & 12 & \\
\hline \multicolumn{2}{|c|}{ Total } & 117 & - \\
\hline
\end{tabular}

\subsection{Standard and Accelerated Carbonation Tests}

The accelerated concrete carbonation test was conducted in accordance with the standard test method for accelerated carbonation of concrete, KS F 2584, and the test for normal carbonation and accelerated carbonation-depth measurement was conducted in accordance with the standard test method for measuring the carbonation depth of concrete, KS F 2596 [31,32]. A carbonation chamber was used, and the acceleration conditions were set to a temperature of $20 \pm 2{ }^{\circ} \mathrm{C}$, the relative humidity of $65 \pm 5 \%$, and $\mathrm{CO}_{2}$ concentration of $5 \pm 0.2 \%$. For the carbonation-depth measurement method, the specimens were split when they reached a predetermined accelerated curing period, and their performances were analyzed using the phenolphthalein solution specified in KS M 8238. In the case of the phenolphthalein solution, an indicator was used, wherein $100 \mathrm{~mL}$ was prepared by dissolving $1 \mathrm{~g}$ of phenolphthalein powder in $95 \mathrm{~mL}$ of $95 \%$ ethanol, followed by the addition of water. When the specimens were very dry, more water was added by adjusting the amount of ethanol to $70 \mathrm{~mL}$. The solution was applied to the measured surfaces with a sprayer, and the discolored sections were measured. The average value was measured for the measured surfaces at 10 points on two sides of a specimen. In addition, the carbonation velocity rate can be derived based on the carbonation depth using Equation (1).

$$
A=\frac{c_{t}}{\sqrt{t}}
$$

where $C_{t}$ is the carbonation depth $(\mathrm{mm}), A$ is the carbonation velocity rate $(\mathrm{mm} / \mathrm{y})$, and $t$ is the time (year).

\subsection{Chloride}

The chloride test was conducted in accordance with NT BUILD 492 (concrete, mortar, and cement-based repair materials; chloride migration coefficient from non-steady-state migration experiments) to derive the chloride depth and chloride diffusion coefficient [33]. The test was conducted as follows: The $\varnothing 100 \times 200 \mathrm{~mm}$ cylindrical specimens were cut to have a thickness of $50 \pm 2 \mathrm{~mm}$. The exterior of the cut specimen was coated with epoxy resin. After placing the specimen in a vacuum desiccator, the absolute pressure 
was reduced to 10-50 mbar (1-5 kPa), and the vacuum condition was maintained for $3 \mathrm{~h}$. $\mathrm{A} \mathrm{Ca}(\mathrm{OH})_{2}$ solution was then added to the specimen to be immersed, and the vacuum condition was maintained for $18 \pm 2 \mathrm{~h}$ to saturate the specimen. The anode part of the saturated specimen was then filled with a $0.3 \mathrm{~N} \mathrm{NaOH}$ solution (approximately $12 \mathrm{~g} \mathrm{NaOH}$ in $1 \mathrm{~L}$ water), and a $10 \% \mathrm{NaCl}$ solution $(100 \mathrm{~g} \mathrm{NaCl}$ in $900 \mathrm{~g}$ water, $\sim 2 \mathrm{~N})$ was added to the cathode, as shown in Figure 6. After the application of an initial voltage of $30 \mathrm{~V}$, the voltage to be applied was determined based on the measurement of the initial current. Finally, measurements were performed for 6-96 h depending on the amount of current.

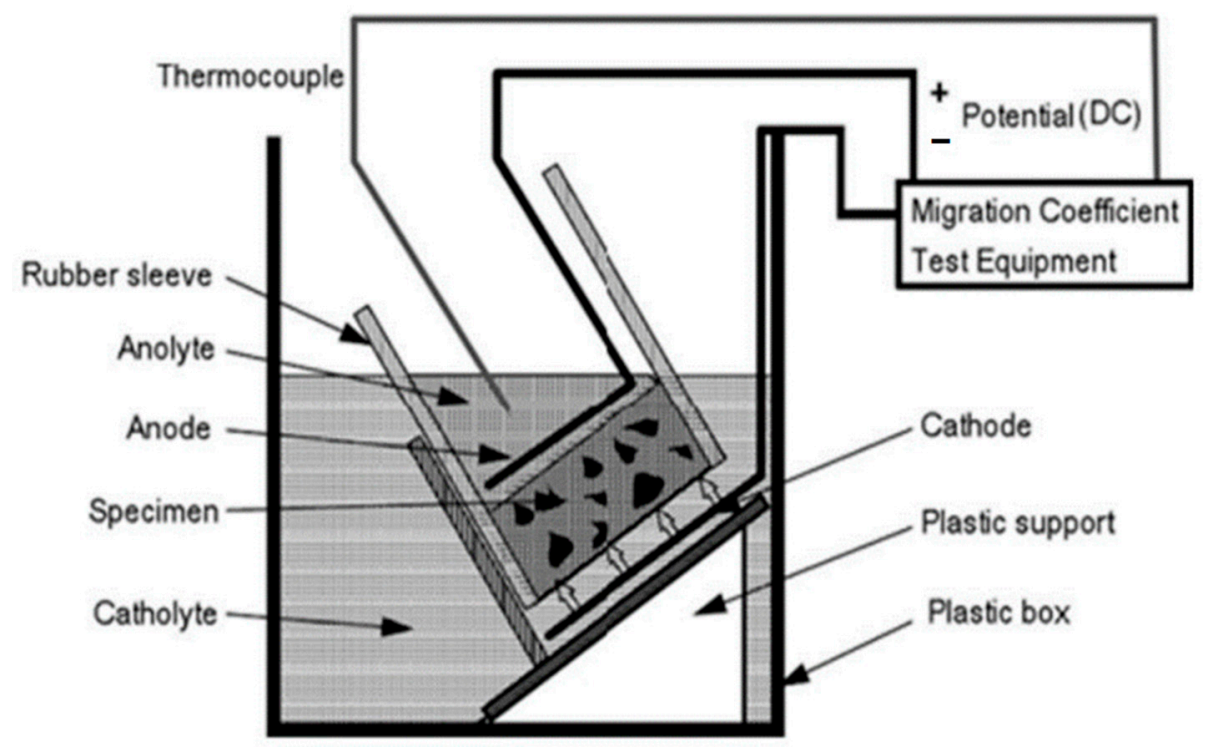

Figure 6. NT Build 492 test method.

The chloride diffusion coefficient was derived based on Equations (2)-(4).

$$
\begin{gathered}
D_{n s s m}=\frac{R T}{z F E} \times \frac{X_{d}-\alpha \sqrt{X_{d}}}{t}, \\
E=\frac{U-2}{L} \\
\alpha=2 \sqrt{\frac{R T}{z F E}} \circ \operatorname{erf}^{-1}\left(1-\frac{2 c_{d}}{c_{0}}\right)
\end{gathered}
$$

where $D_{n s s m}$ is the voltage-accelerated chloride diffusion coefficient obtained in an unsteady state $\left(\mathrm{m}^{2} / \mathrm{s}\right), R$ is the molar gas constant $(8.314 \mathrm{~J} / \mathrm{K} \cdot \mathrm{mol}), T$ is the absolute temperature $(\mathrm{K}), L$ is the specimen thickness $(\mathrm{m}), z$ is the ionic valence ( $z=1$ for chlorides), $F$ is the Faraday constant $(9.648 \times 104 \mathrm{~J} / \mathrm{V} \cdot \mathrm{mol}), U$ is the potential difference $(\mathrm{V}), X_{d}$ is the average penetration depth by calorimetry $(\mathrm{m}), t$ is the application time of the potential difference (s), $C_{0}$ is the chloride ion concentration of the cathode cell $(\fallingdotseq 2 \mathrm{~N}), C_{d}$ is the reaction concentration by colorimetry ( $=0.07 \mathrm{~N}$ for OPC), and erf $^{-1}$ is the inverse of the error function.

\subsection{Freezing and Thawing}

The freeze-thaw tests were conducted in accordance with the standard test method for resistance of concrete to rapid freezing and thawing, KS F 2456 [34]. The specimen size was $\varnothing 100 \times 200 \mathrm{~mm}$, and a freeze-and-thaw chamber was used. One cycle was based on the freezing process in which the temperature of the center of the specimen dropped from 4 to $-18{ }^{\circ} \mathrm{C}$ and the thawing process in which the temperature increased from -18 to $4{ }^{\circ} \mathrm{C}$. In addition, one freeze-thaw cycle was set to be more than two hours and less than four hours. Based on this test, the relative dynamic elastic modulus could be measured at 0 , 
100,200 , and 300 cycles. The reduction rate of the relative dynamic elastic modulus after $N$ cycles can be calculated based on Equation (5). In addition, the durability index for the evaluation of the performance of concrete can be derived using Equation (6).

$$
P_{c}=\left(\frac{n_{c}^{2}}{n_{0}^{2}}\right) \times 100
$$

where $P_{c}$ is the relative dynamic elastic modulus (\%) after $C$ cycles of freezing and thawing, $n_{0}$ is the primary resonance frequency $(\mathrm{Hz})$ of deformation vibration at the 0 th cycle, and $n_{c}$ is the primary resonance frequency $(\mathrm{Hz})$ of deformation vibration after $C$ cycles.

$$
D F=P N / M
$$

where $D F$ is the durability index of the specimen, $P$ is the relative dynamic elastic modulus $(\%)$ at $N$ cycles, $N$ is the number of cycles at which the relative dynamic elastic modulus becomes $60 \%$, and $M$ is the number of cycles when exposed to freezing and thawing.

\section{Experimental Durability Results}

\subsection{Compressive Strength Results}

Table 3 and Figure 7 present the concrete core compressive strength results. The compressive strengths of the control specimens with design strengths of 20,30, and $40 \mathrm{MPa}$ were found to be 22.3, 30.0, and $44.1 \mathrm{MPa}$, respectively. These outcomes satisfied the design strengths. The compressive strengths after epoxy and impregnating repair exceeded the design strengths of 20 and $30 \mathrm{MPa}$. The epoxy/impregnating repair method also recovered performance as much as the control specimens. In particular, the impregnating repair method exhibited approximately $10-20 \%$ higher performance than the control specimens. In the case of the design strength of $40 \mathrm{MPa}$, none of the crack repair methods could recover performance as much as the control specimen, but approximately $90-95 \%$ recovery could be achieved. Based on these results, it was found that the impregnating repair method was the most effective, and the epoxy/impregnating repair method tended to exhibit low performance for all the design strengths. Essentially, impregnating demonstrates the effect of forming dense capillary pores through its reaction with calcium hydroxide in concrete. It appears that the epoxy/impregnating repair method, wherein impregnation was applied after epoxy injection, could not exhibit a sufficient absorption effect of the impregnation, owing to the epoxy.

\begin{tabular}{|c|c|c|}
\hline Design Strength (MPa) & Repair Method & Compressive Strength (MPa) \\
\hline \multirow{4}{*}{20} & Control & 23.3 \\
\hline & Epoxy & 23.5 \\
\hline & Impregnating & 27.3 \\
\hline & Epoxy/Impregnating & 22.9 \\
\hline \multirow{4}{*}{30} & Control & 30.0 \\
\hline & Epoxy & 33.2 \\
\hline & Impregnating & 34.1 \\
\hline & Epoxy/Impregnating & 29.9 \\
\hline \multirow{4}{*}{40} & Control & 44.1 \\
\hline & Epoxy & 40.3 \\
\hline & Impregnating & 42.3 \\
\hline & Epoxy/Impregnating & 41.0 \\
\hline
\end{tabular}

Table 3. Compressive strength test results. 


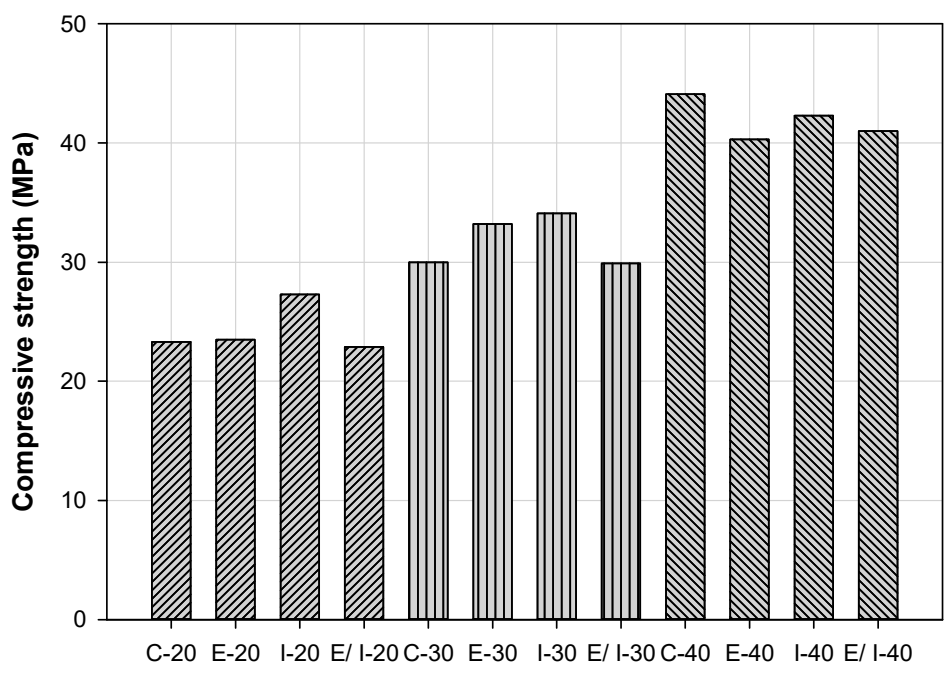

Specimens

Figure 7. Compressive strength responses for various concrete specimens.

As shown, if an additional continuous cyclic load is applied to a crack in the concrete structure, the structural performance may rapidly deteriorate. It can mainly appear in infrastructure such as bridges, roads, railroads, and dams, where their failure can cause damage to humans. Therefore, it is judged that concrete strength performance can be improved based on impregnating repair.

\subsection{Standard and Accelerated Carbonation Test Results}

Table 4 and Figures 8-10 present the standard concrete and accelerated carbonationdepth results. For the design strengths of 20,30, and $40 \mathrm{MPa}$, the specimens without cracks were compared with those repaired using the epoxy, impregnating, and epoxy/impregnating repair methods owing to cracks. In the case of the specimens without cracks, the carbonation depths for the design strengths of 20,30, and $40 \mathrm{MPa}$ were found to be approximately $14.5,7.3$, and $4.1 \mathrm{~mm}$, respectively. This is because $\mathrm{CO}_{2}$ penetration from the outside is difficult for high-strength concrete owing to the high internal watertightness. In addition, the carbonation depths at 1 and 4 weeks of age according to the crack repair method are as follows: For a design strength of $20 \mathrm{MPa}$ at 4 weeks of age, the carbonation depths of the epoxy and impregnating repair methods increased by approximately 1.5 times, but the epoxy/impregnating repair method exhibited a carbonation depth similar to that at 1 week of age. Similarly, for a design strength of $30 \mathrm{MPa}$ at 4 weeks of age, the carbonation depths of the epoxy and impregnating repair methods increased by approximately 1.3 times, but the epoxy/impregnating repair method exhibited a carbonation depth similar to that at 1 week of age. For a design strength of $40 \mathrm{MPa}$ at 4 weeks of age, however, the epoxy and epoxy/impregnating repair methods exhibited carbonation depths similar to those at 1 week of age, but the carbonation depth of the epoxy/impregnating repair method almost doubled compared with the results of 20 and $30 \mathrm{MPa}$. In addition, as the design strength increased, the carbonation depths at 4 weeks of age exhibited a tendency to decrease owing to the repair methods. Therefore, in the case of the epoxy/impregnating repair method at $40 \mathrm{MPa}$, it is expected that more accurate results can be derived by obtaining more data. The carbonation velocity rate exhibited a tendency similar to that of the carbonation depth because it was derived based on the latter itself. Then, epoxy filling and epoxy/impregnating repair methods help resist and reduce carbon dioxide penetration from the environment.

When carbon dioxide penetrates the structure along the crack, it adheres to the reinforcing bar, destroys the surface passive film of the reinforcing bar, and causes rust. When the reinforcing bar is corroded, it expands, resulting in additional cracks and detachment in the concrete internal structure. If this repeatedly occurs, the performance of the structure 
degrades rapidly, and durability performance can be improved by epoxy/impregnating repair. In addition, it can be used for various roads and bridges.

Table 4. Accelerated carbonation test results.

\begin{tabular}{|c|c|c|c|c|c|c|}
\hline \multirow{2}{*}{$\begin{array}{l}\text { Design Strength } \\
\text { (MPa) }\end{array}$} & \multirow[t]{2}{*}{ Repair Method } & \multirow{2}{*}{$\begin{array}{c}\text { Carbonation } \\
\text { Depth } \\
\text { (Noncrack) (mm) }\end{array}$} & \multicolumn{2}{|c|}{ Carbonation Depth (mm) } & \multicolumn{2}{|c|}{$\begin{array}{l}\text { Carbonation Speed Modulus } \\
\qquad(\mathrm{mm} / \sqrt{\text { week }})\end{array}$} \\
\hline & & & 1 Week & 4 Weeks & 1 Week & 4 Weeks \\
\hline \multirow{4}{*}{20} & Control & & - & 18.4 & - & 9.2 \\
\hline & Epoxy & 13.9 & 17.0 & 34.4 & 8.5 & 17.2 \\
\hline & Impregnating & 15.1 & 17.4 & 26.9 & 8.7 & 13.45 \\
\hline & Epoxy/Impregnating & 14.4 & 14.5 & 15.0 & 7.25 & 7.5 \\
\hline \multirow{4}{*}{30} & Control & & - & 12.3 & & 6.15 \\
\hline & Epoxy & 6.2 & 7.1 & 10.7 & 3.55 & 5.35 \\
\hline & Impregnating & 5.8 & 12.1 & 20.3 & 6.05 & 10.15 \\
\hline & Epoxy/Impregnating & 9.9 & 11.3 & 12.2 & 5.65 & 6.1 \\
\hline \multirow{4}{*}{40} & Control & & - & 3.0 & & 1.5 \\
\hline & Epoxy & 2.9 & 5.4 & 5.8 & 2.7 & 2.9 \\
\hline & Impregnating & 4.5 & 9.1 & 12.2 & 4.55 & 6.1 \\
\hline & Epoxy/Impregnating & 5.0 & 15.9 & 28.2 & 7.95 & 14.4 \\
\hline
\end{tabular}

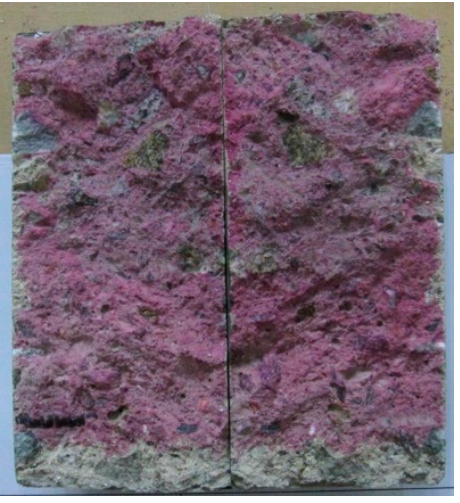

(a)

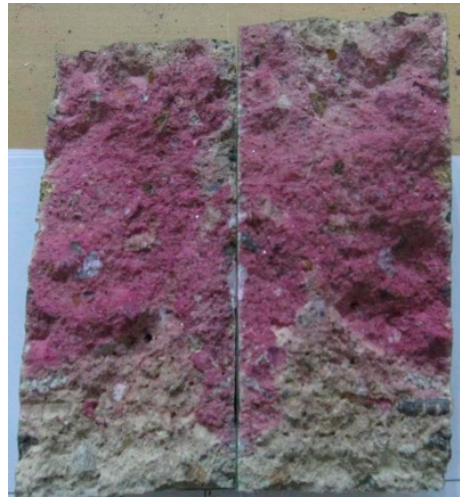

(b)

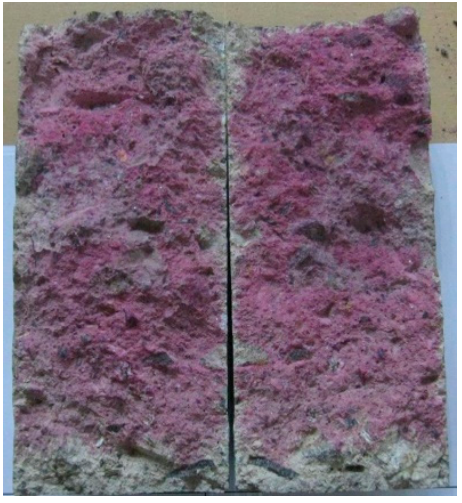

(c)

Figure 8. Carbonation depth: (a) epoxy repair, (b) impregnating repair, and (c) epoxy/impregnating repair.

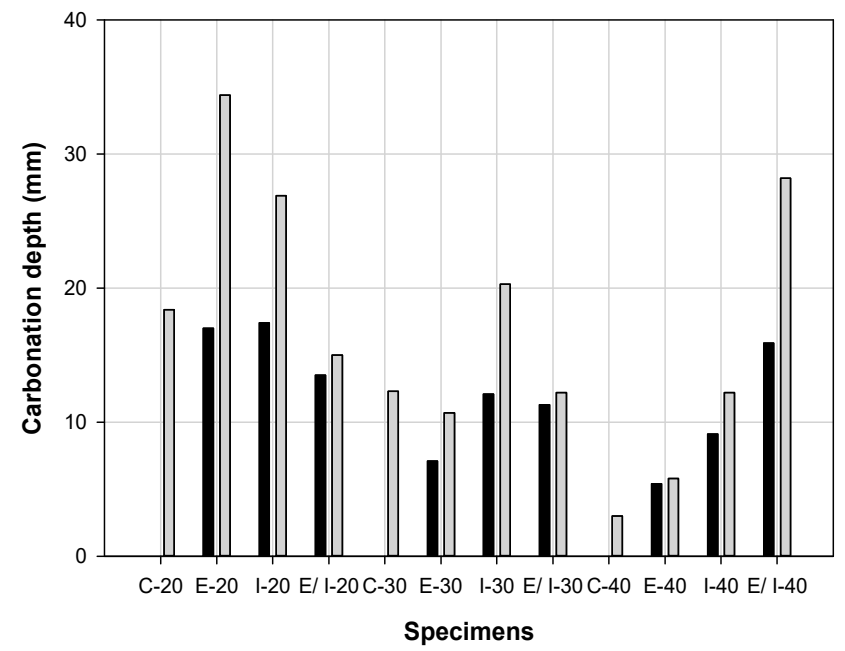

Figure 9. Concrete carbonation depth responses for different test specimens. 


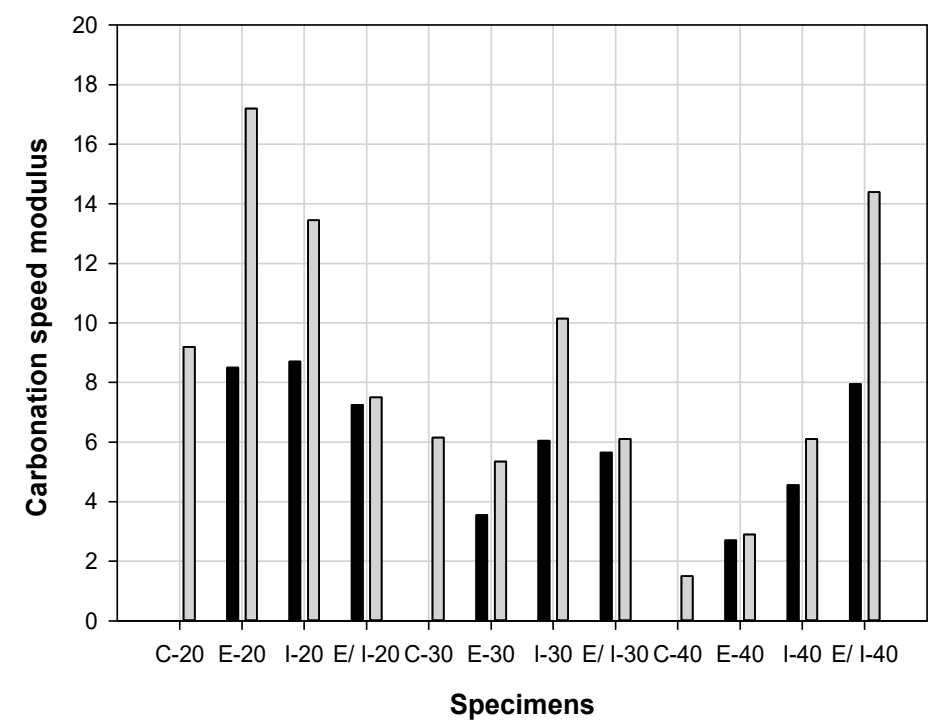

Figure 10. Concrete carbonation speed modulus responses for different test specimens.

\subsection{Chloride Test Results}

Table 5 and Figures 11-13 present the concrete chloride depths and diffusion coefficients, respectively. The chloride depths of the control specimens with design strengths of 20,30, and $40 \mathrm{MPa}$ were found to be $9.4,5.1$, and $4.4 \mathrm{~mm}$, respectively. For a design strength of $20 \mathrm{MPa}$, the chloride depths of the epoxy, impregnating, and epoxy/impregnating repair methods were $14.2,37.5$, and $14.4 \mathrm{~mm}$, respectively. These were approximately $1.5,4$, and 1.5 times higher than that of the control specimen, respectively. For a design strength of $30 \mathrm{MPa}$, the chloride depths of the epoxy, impregnating, and epoxy/impregnating repair methods were $6.8,25.9$, and $7.9 \mathrm{~mm}$, which were approximately $1.2,5$, and 1.5 times higher than that of the control specimen, respectively. For a design strength of $40 \mathrm{MPa}$, the chloride depths of the epoxy, impregnating, and epoxy/impregnating repair methods were 2.5, 5.7, and $2.7 \mathrm{~mm}$, respectively. The chloride depths of the epoxy and impregnating repair methods were approximately 0.5 times lower than that of the control specimen, but the chloride depth of the epoxy/impregnating repair method was 1.2 times higher. As the design strength increased, the repair effect was found to be larger for the epoxy, impregnating, and epoxy/impregnating repair methods. The epoxy repair method exhibited the highest performance improvement, followed by the epoxy/impregnating and impregnating repair methods. Impregnating repair exhibited a smaller repair effect than epoxy repair. It appears that the chloride depth became higher for the impregnating repair method because cracks were generated from the existing cracks during the second loading after the repairs in the flexural strength test. By contrast, cracks were mainly generated at new locations for the epoxy and epoxy/impregnating repair methods. The chloride diffusion coefficient exhibited the same phenomenon as that exhibited by the chloride depth because it was derived based on the latter itself. Especially, by filling the cracks with epoxy, crack penetration from chloride damage reduced significantly as the epoxy behaves as an integral part of the concrete structure.

Chloride exhibits a similar form to carbonation infiltration, causing corrosion of reinforcing bars due to chloride infiltration and rapid deterioration of the structure. As a method to prevent such performance degradation, the durability performance may be improved by epoxy and epoxy/impregnating repair. In addition, it is regarded as considerably advantageous for coastal areas.

\subsection{Test Results of Freezing-Thawing Test}

Table 6 and Figure 14 present the relative dynamic elastic moduli at 0, 100, 200, and 300 cycles based on the freezing-thawing test. Among the design strengths of 20, 30 , and $40 \mathrm{MPa}, 20 \mathrm{MPa}$ led to damage because the measurement was not possible at 
300 cycles. For 30 and $40 \mathrm{MPa}$, the relative dynamic elastic moduli at 300 cycles were measured to be 26 and $32.5 \%$, respectively. In the case of the design strength of $20 \mathrm{MPa}$, the epoxy/impregnating repair method exhibited the highest relative dynamic elastic modulus of $41.4 \%$ for $0-300$ cycles. For a design strength of $30 \mathrm{MPa}$, the epoxy, impregnating, and epoxy/impregnating repair methods exhibited approximately 1.8, 1.5, and 1.7 times higher relative dynamic elastic moduli than the control specimen after 300 cycles. For a design strength of $40 \mathrm{MPa}$, the epoxy, impregnating, and epoxy/impregnating repair methods exhibited approximately 1.5, 0.8, and 2.1 times higher relative dynamic elastic moduli than the control specimen after 300 cycles. As described previously, the impregnating repair method exhibited rapid performance degradation over 200 cycles owing to the more obvious crack occurrence. The epoxy/impregnating repair method was considered to have the most excellent crack repair effect because it exhibited higher relative dynamic elastic moduli than the epoxy and impregnating repair methods at 100, 200, and 300 cycles.

Table 5. Chloride test results.

\begin{tabular}{|c|c|c|c|}
\hline Design Strength (MPa) & Repair Method & $\begin{array}{l}\text { Chloride Depth } \\
(\mathrm{mm})\end{array}$ & $\begin{array}{l}\text { Chloride Diffusion Coefficient } \\
\qquad\left(\times 10^{-12} \mathrm{~m}^{2} / \mathrm{s}\right)\end{array}$ \\
\hline \multirow{4}{*}{20} & Control & 9.4 & $8.76 \times 10^{-12}$ \\
\hline & Epoxy & 14.2 & $1.31 \times 10^{-11}$ \\
\hline & Impregnating & 37.5 & $3.76 \times 10^{-11}$ \\
\hline & Epoxy/Impregnating & 14.4 & $1.33 \times 10^{-11}$ \\
\hline \multirow{4}{*}{30} & Control & 5.1 & $4.38 \times 10^{-12}$ \\
\hline & Epoxy & 6.8 & $5.71 \times 10^{-12}$ \\
\hline & Impregnating & 25.9 & $2.46 \times 10^{-11}$ \\
\hline & Epoxy/Impregnating & 7.9 & $6.84 \times 10^{-12}$ \\
\hline \multirow{4}{*}{40} & Control & 4.4 & $3.65 \times 10^{-12}$ \\
\hline & Epoxy & 2.5 & $1.87 \times 10^{-12}$ \\
\hline & Impregnating & 5.7 & $5.55 \times 10^{-12}$ \\
\hline & Epoxy/Impregnating & 2.7 & $1.94 \times 10^{-12}$ \\
\hline
\end{tabular}

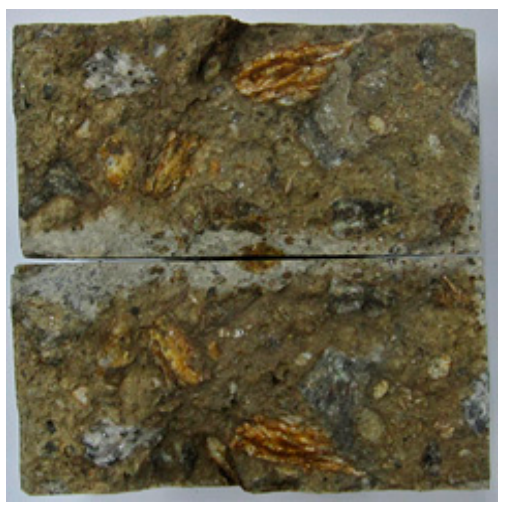

(a)

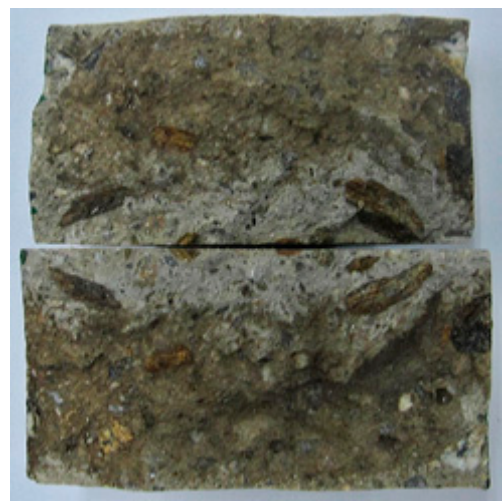

(b)

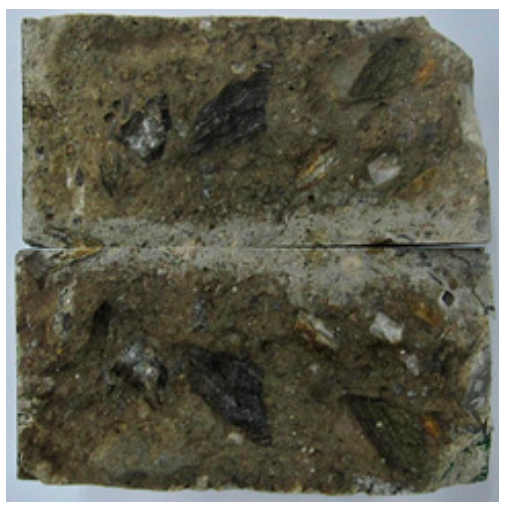

(c)

Figure 11. Chloride depth: (a) epoxy repair, (b) impregnating repair, and (c) epoxy/impregnating repair.

Table 7 and Figure 15 present the concrete compressive strengths after the 300th cycle of the freezing-thawing tests. The compressive strengths of the control specimens with design strengths of 20,30, and $40 \mathrm{MPa}$ were found to be $16.5,23.9$, and $35.3 \mathrm{MPa}$, respectively, which were approximately $23 \%$ lower than the design strengths owing to the durability degradation. In the case of a design strength of $20 \mathrm{MPa}$, the impregnating and epoxy/impregnating repair methods recovered the design strength of $20 \mathrm{MPa}$. For a design strength of $30 \mathrm{MPa}$, none of the repair methods could recover the design strength, 
but they exhibited strengths higher than that of the control specimen. For a high strength of $40 \mathrm{MPa}$, however, none of the repair methods could recover the design strength, and they exhibited strengths lower than that of the control specimen. In addition, it was found that the repair methods that included impregnating exhibited higher compressive strength after the freeze-thaw cycles.

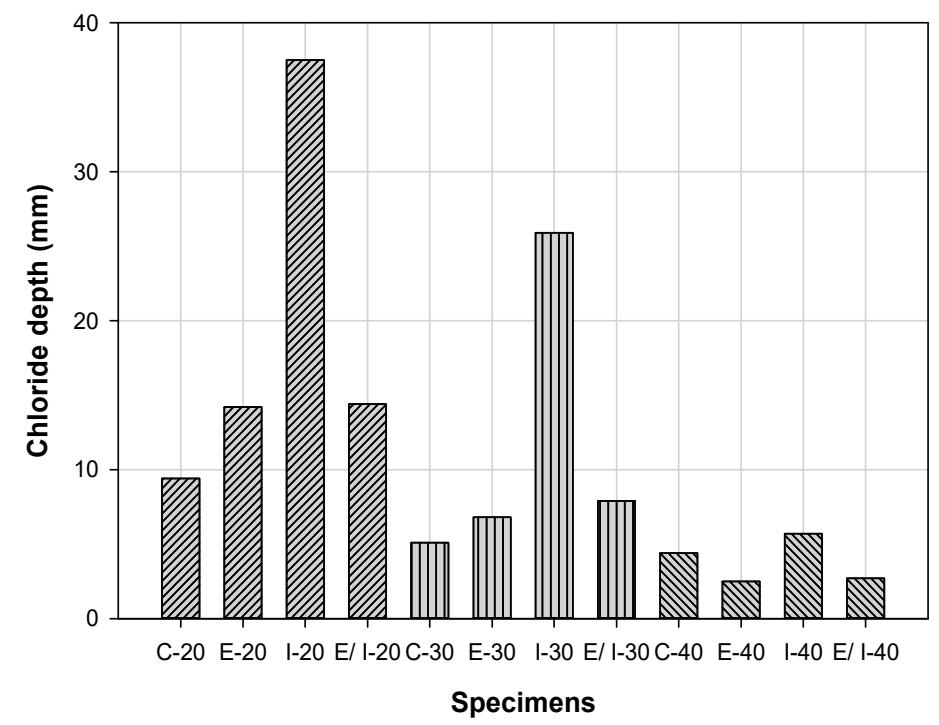

Figure 12. Chloride depth responses for different concrete specimens.

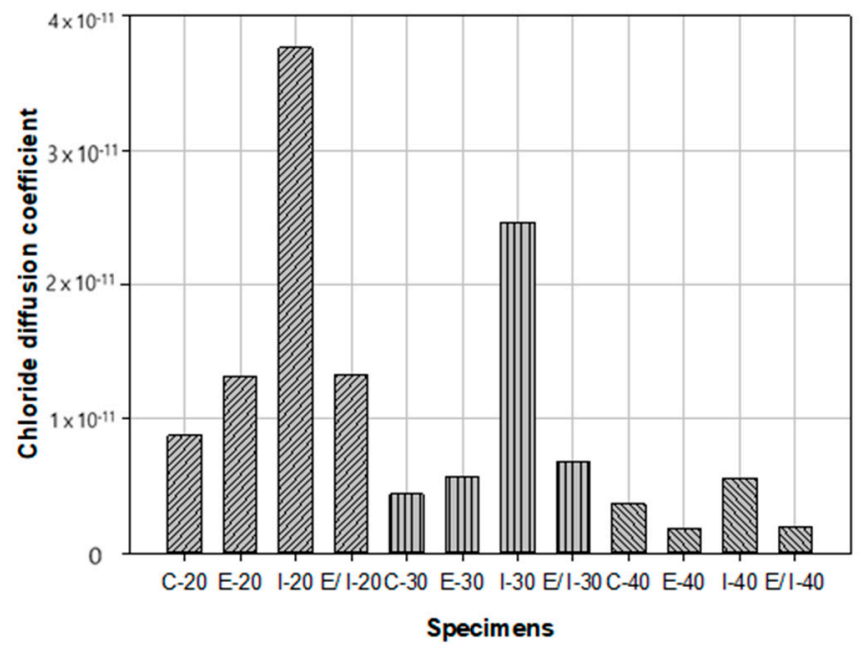

Figure 13. Chloride diffusion coefficient responses for different concrete specimens.

Table 6. Freezing and thawing test results.

\begin{tabular}{|c|c|c|c|c|c|}
\hline \multirow{2}{*}{$\begin{array}{l}\text { Design Strength } \\
\text { (MPa) }\end{array}$} & \multirow{2}{*}{ Repair Method } & \multicolumn{4}{|c|}{ Relative Elastic Modulus (\%) } \\
\hline & & 0th Cycle & 100th Cycle & 200th Cycle & 300th Cycle \\
\hline \multirow{4}{*}{20} & Control & 100 & 73.0 & 54.4 & - \\
\hline & Epoxy & 100 & 77.9 & 54.8 & 27.7 \\
\hline & Impregnating & 100 & 75.5 & 43.4 & - \\
\hline & Epoxy/Impregnating & 100 & 80.3 & 52.1 & 41.1 \\
\hline \multirow{4}{*}{30} & Control & 100 & 71.9 & 60.4 & 26.0 \\
\hline & Epoxy & 100 & 73.1 & 67.3 & 47.3 \\
\hline & Impregnating & 100 & 68.9 & 52.1 & 38.7 \\
\hline & Epoxy/Impregnating & 100 & 82.8 & 69.7 & 44.0 \\
\hline
\end{tabular}


Table 6. Cont.

\begin{tabular}{|c|c|c|c|c|c|}
\hline \multirow{2}{*}{$\begin{array}{l}\text { Design Strength } \\
\text { (MPa) }\end{array}$} & \multirow{2}{*}{ Repair Method } & \multicolumn{4}{|c|}{ Relative Elastic Modulus (\%) } \\
\hline & & 0th Cycle & 100th Cycle & 200th Cycle & 300th Cycle \\
\hline \multirow{4}{*}{40} & Control & 100 & 77.5 & 60.2 & 32.5 \\
\hline & Epoxy & 100 & 71.1 & 65.7 & 51.2 \\
\hline & Impregnating & 100 & 76.2 & 51.9 & 25.8 \\
\hline & Epoxy/Impregnating & 100 & 83.7 & 73.2 & 66.0 \\
\hline
\end{tabular}

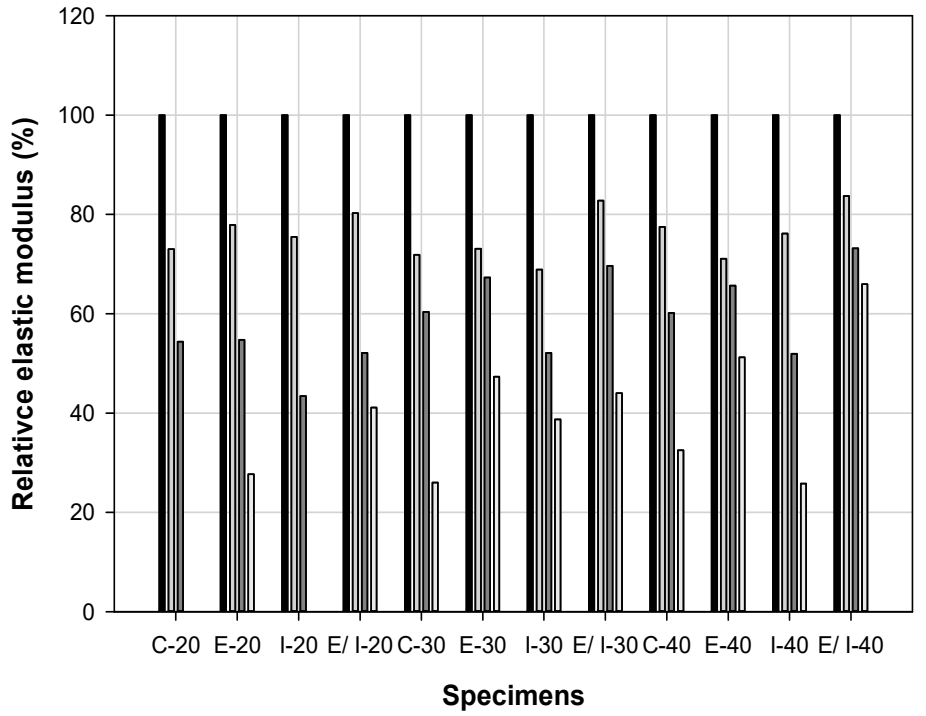

Figure 14. Relative elastic modulus responses of various test specimens.

Table 7. Freezing and thawing compressive strength results.

\begin{tabular}{|c|c|c|}
\hline Design Strength (MPa) & Repair Method & Compressive Strength (MPa) \\
\hline \multirow{4}{*}{20} & Control & 16.5 \\
\hline & Epoxy & 16.4 \\
\hline & Impregnating & 20.7 \\
\hline & Epoxy/Impregnating & 20.2 \\
\hline \multirow{4}{*}{30} & Control & 23.9 \\
\hline & Epoxy & 25.2 \\
\hline & Impregnating & 26.4 \\
\hline & Epoxy/Impregnating & 26.2 \\
\hline \multirow{4}{*}{40} & Control & 35.3 \\
\hline & Epoxy & 32.6 \\
\hline & Impregnating & 33.1 \\
\hline & Epoxy/Impregnating & 31.6 \\
\hline
\end{tabular}

Freeze-thawing causes moisture to penetrate through cracks in concrete structures, and by repeated freezing and thawing, the structure may expand, resulting in dangerous situations such as concrete detachment. Especially in cold areas, it can occur in places that may be exposed to water. In the case of freeze-thawing, it is believed that durability performance can be improved based on epoxy/impregnating repair. 


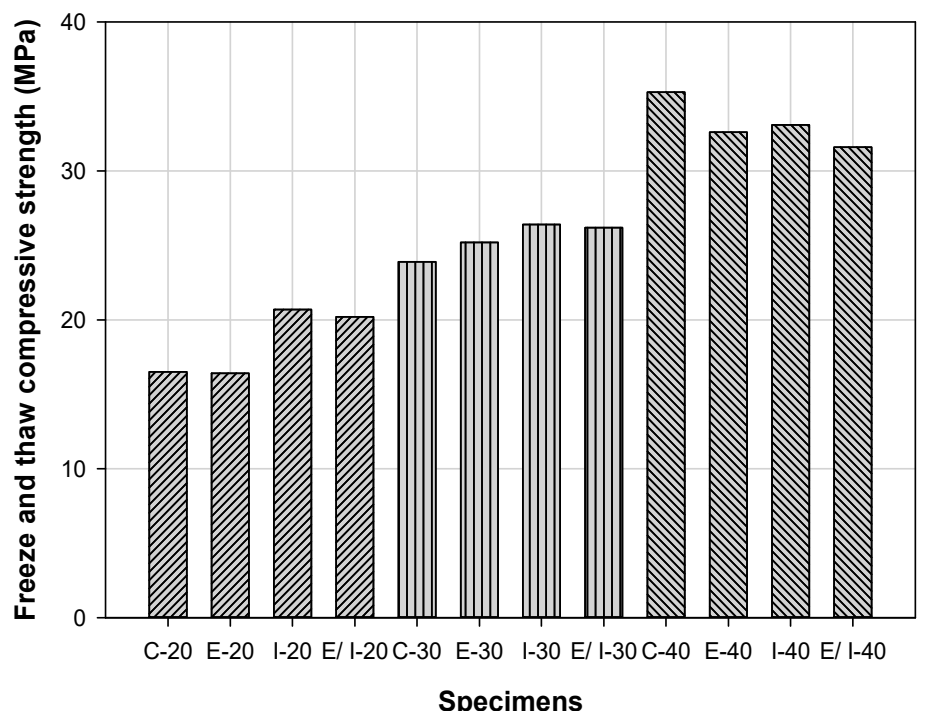

Figure 15. Compressive strength responses following freezing and thawing for various concrete specimens.

\section{Conclusions}

In this study, activated cracks were described through flexural strength tests on concrete specimens, and their structural performance was evaluated using the epoxy, impregnating, and epoxy/impregnating repair methods. Subsequently, carbonation, chloride, and freezing-thawing tests were conducted on the concrete core specimens. The results of this study can be summarized as follows:

(1) For concrete design strengths of 20 and $30 \mathrm{MPa}$, the compressive strengths of the epoxy and impregnating repair methods exceeded the design strengths, and the epoxy/impregnating repair method recovered performance as much as the control specimens. In the case of the design strength of $40 \mathrm{MPa}$, none of the repair methods could recover performance as much as the control specimen. Approximately $90 \%$ recovery was achieved. In particular, impregnating repair increased the watertightness of the specimen and improved performance by approximately $10-20 \%$.

(2) In the case of carbonation resistance performance, for design strengths of 20 and $30 \mathrm{MPa}$, the carbonation depths of the epoxy and impregnating repair methods increased by approximately 1.3 times, but the epoxy/impregnating repair method exhibited a carbonation depth similar to that at one week of age. For a design strength of $40 \mathrm{MPa}$, however, the epoxy and impregnating repair methods exhibited carbonation depths similar to those at 1 week of age, but the carbonation depth of the epoxy/impregnating repair method increased considerably.

(3) In the case of chloride resistance performance, for design strengths of 20,30, and $40 \mathrm{MPa}$, the chloride depths of both the epoxy and epoxy/impregnating repair methods were approximately 1.5 times higher than those of the control specimen, but the impregnating repair method exhibited $4-5$ times higher chloride depths. This appears to be attributed to the additional cracks generated from the existing cracks for the impregnating repair method during the flexural strength test after repair.

(4) The freezing-thawing test results revealed that the relative dynamic elastic modulus exceeded $70 \%$ for the epoxy and impregnating repair methods and $80 \%$ for the epoxy /impregnating repair method at 100 cycles for the design strengths of 20,30, and $40 \mathrm{MPa}$. After 200 cycles, however, a more obvious occurrence of cracks was observed. In addition, rapid performance degradation occurred, and the impregnating repair method exhibited faster performance degradation than the epoxy repair method at 300 cycles. 
(5) Physical and environmental conditions must be considered when repair methods are implemented for concrete structures with activated cracks. The impregnating repair method yielded the highest strength performance. The epoxy/impregnating repair method was the most suitable for carbonation, the epoxy and epoxy/impregnating repair methods for chloride, and the epoxy/impregnating repair method for freezethaw durability. In addition, the most suitable repair method varied depending on the design strength.

(6) As mentioned previously, various conditions must be considered when repair methods are applied to actual structures. To obtain more accurate repair method data, further research on more repair methods, crack sizes, and repair materials is required in the future.

Author Contributions: Conceptualization, T.-K.K. and J.-S.P.; Data Curation, T.-K.K. and J.-S.P.; Formal analysis, T.-K.K. and J.-S.P.; Investigation, T.-K.K. and J.-S.P.; Methodology, T.-K.K. and J.-S.P.; Project administration, J.-S.P.; Resources, T.-K.K.; Software, T.-K.K.; Supervision, J.-S.P.; Validation, T.-K.K. and J.-S.P.; Visualization, T.-K.K. and J.-S.P.; Writing—original draft, T.-K.K.; Writingreview and editing, T.-K.K. and J.-S.P. All authors have read and agreed to the published version of the manuscript.

Funding: This research was funded by the Smart Civil Infrastructure Research Program for the Ministry of Land, Infrastructure, and Transport of the Korean Government, grant number 17SCIPB128496-01.

Institutional Review Board Statement: Not applicable.

Informed Consent Statement: Not applicable.

Data Availability Statement: The data presented in this study are available on request from the corresponding author.

Acknowledgments: This research was supported by a grant (17SCIP-B128496-01) from the Smart Civil Infrastructure Research Program funded by the Ministry of Land, Infrastructure and Transport of the Korean government.

Conflicts of Interest: The author declares no conflict of interest.

\section{References}

1. Kim, T.K.; Choi, S.J.; Choi, J.H.; Kim, J.H.J. Prediction of chloride penetration depth rate and diffusion coefficient rate of concrete from curing condition variations due to climate change effect. Int. J. Concr. Struct. Mater. 2013, 13, 15. [CrossRef]

2. Mehta, P.K.; Paulo, J.M.M. Concrete (Microstructure, Properties, and Materials), 3rd ed.; McGraw Hill: New York, NY, USA, 2006.

3. Sidney, M.; Francis, Y.; David, D. Concrete, 2nd ed.; Prentice Hall: Upper Saddle River, NJ, USA, 2003.

4. International Organization for Standardization. Maintenance and Repair of Concrete Structures; ISO 16311; Vernier: Geneva, Switzerland, 2014.

5. British Standards Institution. Products and System for the Protection and Repair of Concrete Structures; BS EN 1504; British Standards Institution: London, UK, 2005.

6. American Concrete Institute (ACI). Code Requirements for Assessment, Repair, and Rehabilitation of Existing Concrete Structures and Commentary; ACI 562; American Concrete Institute (ACI): Farmington Hills, MI, USA, 2016.

7. Ministry of Land, Infrastructure, and Transport. Detailed Guidelines on Safety Inspection and Precision Safety Diagnosis; Report No. RD-12-E6-024; Korea Authority of Land \& Infrastructure Safety: Jinju, Korea, 2017. (In Korean)

8. Park, J.S.; Park, K.T.; Park, H.B.; Kim, B.C. Concrete repair and rehabilitation code and post-reinforcement evaluation technology. J. Korea Concr. Inst. 2018, 30, 21-26. (In Korean)

9. Petrounias, P.; Giannakopoulou, P.P.; Rogkala, A.; Stamatis, P.M.; Tsikouras, B.; Papoulis, D.; Lampropoulou, P.; Hatzipanagiotou, $\mathrm{K}$. The influence of alteration of aggregates on the quality of the concrete: A case study from serpentinites and andesites from central Macedonia (North Greece). Geosciences 2018, 8, 115. [CrossRef]

10. Issa, C.A.; Debs, P. Experimental study of epoxy repairing of cracks in concrete. Constr. Build. Mater. 2007, 21, 157-163. [CrossRef]

11. Christodoulou, C.; Goodier, C.I.; Austin, S.A.; Webb, J.; Glass, G.K. Long-term performance of surface impregnation of reinforced concrete structures with silane. Constr. Build. Mater. 2013, 48, 708-716. [CrossRef]

12. Kang, S.P.; Hong, S.J. Bending strength and fracture energy of repaired concrete specimen by crack repair material. J. Archit. Inst. Korea Struct. Const. 2009, 25, 161-168. (In Korean)

13. Bae, J.S.; Kim, H.J.; Park, G.J.; Han, J.W. Characteristics of concrete impregnated with inorganic surface penetration agents. J. Korea Inst. Concr. Struct. Maint. Insp. 2010, 14, 71-77. (In Korean) 
14. Kwon, S.J.; Park, S.S.; Lee, S.M.; Kim, J.W. Selection of concrete surface impregnation through durability tests. J. Korea Inst. Concr. Struct. Maint. Insp. 2007, 11, 77-87. (In Korean)

15. Chang, C.F.; Chen, J.W. Experimental investigation of concrete-carbonation depth. Cem. Concr. Res. 2006, 36, 1760-1767. [CrossRef]

16. Khunthongkeaw, J.; Tangtermsirikul, S.; Leelawat, T. A study on carbonation depth prediction for fly ash concrete. Constr. Build. Mater. 2006, 20, 744-753. [CrossRef]

17. Cho, H.C.; Ju, H.; Oh, J.Y.; Lee, K.J.; Hahm, K.W.; Kim, K.S. Estimation of concrete carbonation depth considering multiple influencing factors on the deterioration of durability for reinforced concrete structures. Adv. Mater. Sci. Eng. 2016, 2016, 4814609. [CrossRef]

18. Farahani, A.; Taghaddos, H.; Shekarchi, M. Prediction of long-term chloride diffusion in silica fume concrete in a marine environment. Cem. Concr. Compos. 2015, 59, 10-17. [CrossRef]

19. Sun, G.; Zhang, Y.; Sun, W.; Liu, Z.; Wang, C. Multi-scale prediction of the effective chloride diffusion coefficient of concrete. Constr. Build. Mater. 2011, 25, 3820-3831. [CrossRef]

20. Jiang, L.; Niu, D.; Yuan, L.; Fei, Q. Durability of concrete under sulfate attack exposed to freeze-thaw cycles. Cold Reg. Sci. Technol. 2015, 112, 112-117. [CrossRef]

21. Zhang, P.; Wittmann, F.H.; Vogel, M.; Müller, H.S.; Zhao, T. Influence of freeze-thaw cycles on capillary absorption and chloride penetration into concrete. Cem. Concr. Res. 2017, 100, 60-67. [CrossRef]

22. Han, S.H.; Park, W.S.; Yang, E.I. Evaluation of concrete durability due to carbonation in harbor concrete structures. Constr. Build. Mater. 2013, 48, 1045-1049. [CrossRef]

23. Silva, R.V.; Neves, R.; De Brito, J.; Dhir, R.K. Carbonation behavior of recycled aggregate concrete. Cem. Concr. Compos. 2015, 62, 22-32. [CrossRef]

24. Němeček, J.; Kruis, J.; Koudelka, T.; Krejčí, T. Simulation of chloride migration in reinforced concrete. Appl. Math. Comput. 2018, 319, 575-585. [CrossRef]

25. Wang, J.; Basheer, P.M.; Nanukuttan, S.V.; Long, A.E.; Bai, Y. Influence of service loading and the resulting microcracks on chloride resistance of concrete. Constr. Build. Mater. 2016, 108, 56-66. [CrossRef]

26. Kim, T.K.; Choi, S.J.; Kim, J.H.J.; Chu, Y.S.; Yu, E. Performance-based evaluation of carbonation resistance of concrete according to various curing conditions from climate change effect. Int. J. Concr. Struct. Mater. 2017, 11, 687-700. [CrossRef]

27. Jiang, W.Q.; Shen, X.H.; Xia, J.; Mao, L.X.; Yang, J.; Liu, Q.F. A numerical study on chloride diffusion in freeze-thaw affected concrete. Constr. Build. Mater. 2018, 179, 553-565. [CrossRef]

28. Yun, Y.; Wu, Y.F. Durability of CFRP-concrete joints under freeze-thaw cycling. Cold Reg. Sci. Technol. 2011, 65, 401-412. [CrossRef]

29. Ma, Z.; Zhu, F.; Ba, G. Effects of freeze-thaw damage on the bond behavior of concrete and enhancing measures. Constr. Build. Mater. 2019, 196, 375-385. [CrossRef]

30. Korea Standards Association (KSA). Standard Test Method for Compressive Strength of Concrete; KS F 2405; Korea Standards Association (KSA): Seoul, Korea, 2017.

31. Korea Standards Association (KSA). Standard Test Method for Accelerated Carbonation of Concrete; KS F 2584; Korea Standards Association (KSA): Seoul, Korea, 2020.

32. Korea Standards Association (KSA). Standard Test Method for Measuring Carbonation Depth of Concrete; KS F 2596; Korea Standards Association (KSA): Seoul, Korea, 2019.

33. Nordtest. Chloride Migration Coefficient from Non-Steady-State Migration Experiments; NT Build 492; Nordtest: Espoo, Finland, 1999.

34. Korea Standards Association (KSA). Standard Test Method for Resistance of Concrete to Rapid Freezing and Thawing; KS F 2456; Korea Standards Association (KSA): Seoul, Korea, 2013. 